\section{Climate Variability and the Emergence of Malaria: Case of Kumbo Central Sub-Division, North West Region, Cameroon}

\author{
Yufenyuy Mohamed (Corresponding Author) \\ European University of Lefke, Institute of Graduate Studies and Research, Department \\ of Environmental sciences, Northern Cyprus TR-10 Mersin, Turkey \\ University of Dschang, Faculty of Letters and Social Sciences, Department of \\ Geography, Laboratory of Climatology and Environmental Research, Cameroon \\ E-mail: papahodja@gmai.com

\begin{abstract}
Nguetsop Victor François
University of Dschang, Faculty of Science, Department of Plant Biology, Laboratory of Applied Biology, Cameroon

E-mail: vfnguetsop@yahoo.fr
\end{abstract}

Received: June 29, 2020 Accepted: November 10, 2020 Published: November 28, 2020 doi:10.5296/ijgs.v4i1.17263 URL: https://doi.org/10.5296/ijgs.v4i1.17263

\begin{abstract}
Climate variability and change is a major driver of infectious diseases around the world. This study sought to investigate the role of climate variability on the emergence of malaria in the North West region of Cameroon. Both biophysical and socio-economic data were collected for this study. Biophysical data, mainly secondary, was collected from meteorological stations (rainfall and temperature data) and hospitals (malaria morbidity and mortality statistics) in the study area. Socio-economic data were collected from primary sources, mainly, survey of households and hospitals, using semi-structured questionnaires. A total of 164 questionnaires were distributed amongst medical personnel and the general public (aged 18-70 years). Data obtained were analyzed using descriptive and inferential statistics. Findings revealed that patterns of fluctuation in climate parameters did not have a perfect match with rates of prevalence of malaria. However, some relatively significant correlation was found to exist between certain aspects of climate and rates of prevalence of malaria. It was noted that other drivers are involved in influencing rates of prevalence of malaria besides climate variability
\end{abstract}


and change. Amongst the impacts of malaria prevalence on the population were high rates of morbidity and mortality. The population employed treated mosquito bed nets as the main coping strategy for fighting against malaria. The study recommends that the health sector should incorporate the phenomena of climate variability and change into its policy framework, and more research should be conducted to assess other drivers of malaria prevalence in north western Cameroon.

Keywords: Cameroon, Climate Change, Climate variability, Malaria, Parasite, Vector.

\section{Introduction}

Climate variability and change pose severe threats to humanity worldwide. Variations in climate, either at the micro or macro-geographical level influence the survival, reproduction, transmission of disease agents and vectors, and their interaction with the geophysical factors associated with climate such as, precipitation, humidity, ambient and water temperature (Nkuo-Akenji et al., 2006; de Souza et al., 2012; Alemayehu et al., 2015). One of the major health concerns regarding climate variability is the increased prevalence of malaria across the globe especially in the tropics. Malaria is a deadly disease caused by plasmodium parasites that are transmitted to humans through the bite of an infected female anopheles mosquitoes which is also referred to as malaria vector (CDC, 2017, WHO, 2020). Although, malaria in humans is caused by five different plasmodium parasite species [Plasmodium $(P)$ falciparum, Plasmodium $(P)$ malariae, Plasmodium $(P)$ vivax, Plasmodium $(P)$ ovale and Plasmodium $(P)$ knowlesi], only two of these species ( $P$. falciparum and $P$. vivax) pose severe danger to man (WHO, 2020).

The transmission rate depends on the prevailing climatic conditions (temperature, rainfall and humidity), the human host/immunity, the vector and the parasite. The rate at which mosquito larva grows depends on the surrounding temperature conditions, so much such that below $16^{\circ} \mathrm{C}$, the development rate of anopheles mosquito stops and below $14^{\circ} \mathrm{C}$, they die. At the adult stage, their feeding habit is also temperature dependent, such that at $17^{\circ} \mathrm{C}$, the female anopheles feeds on human blood every four days and at $25^{\circ} \mathrm{C}$, they feed every two days (Githeko, 2009). This temperature threshold is supplemented by adequate rainfall amounts and a conducive moist environment for the vector to breed. Each female anopheles mosquito lay their eggs in water (preferably, stagnant shallow water which exist in excess during the rainy season in tropical countries) and later on seek for blood meal to nurture their eggs (preferably human blood). This is when the parasite gets in contact with humans.

The most vulnerable groups of persons highly affected by malaria include; young children, pregnant women (WHO, 2019; WHO, 2020). According to recent reports, almost half of the world's population was at risk of being infected with malaria in 2018, but the most significant cases of morbidity and mortality occur in Sub Saharan African countries (Mordecai et al., 2020). However, cases equally abound in South East Asia, East Mediterranean, Western Pacific and the Americas (WHO, 2020). Malaria is therefore an infectious disease that has a global distribution and a significant health burden. According to the World Malaria Report, about 3.3 Billion people are at risk of being infected with malaria and other developing diseases, and about 1.2 Billion people are at high risk (WHO, 2014). It was reported to have slowed down economic growth in Africa by up to $1.3 \%$ each year and also constituted $10 \%$ of Africa's disease burden. From 2015 to 2017, the World Health Organization (WHO) mentioned that no 


\section{MInstitute ${ }^{\text {Macrothink }}$}

major progress has been made towards malaria control worldwide. In 2017 alone, about 219 million cases were recorded with an estimated death toll of 435000 people (WHO, 2018). The Intergovernmental Panel on Climate Change (IPCC) has concluded that anticipated changes in temperature and rainfall will affect the natural habitats of mosquitoes. This may change the prevalence of the vector or prolong transmission seasons in some areas which may potentially expose new regions and populations to malaria and other vector-borne diseases (Kebedeet al., 2005, IPCC, 2018). Thus, climate change has the potential to intensify the global burden of certain diseases (Perevedentsev et al., 2016; Zolotokrylin and Cherenkova, 2017), including malaria and reverse interrelated developmental gains (WHO, 2014). The WHO and the World Meteorological Organization (WMO) have identified malaria as one of the most climate-sensitive diseases, with glaring evidence suggesting significant associations between changes in temperature, rainfall and humidity and malaria incidence (WHO, 2014; RBM, 2015; RBM-Climate Change Fact Sheet, 2015; RBM - Inclusive Societies Fact Sheet, 2015). Although, malaria can be prevented and cured by highly cost-effective interventions, its control still remains one of the highest priorities on the international health agenda (RBM, 2015). This explains why global goals and targets for malaria are still included in many organizations such as the Sustainable Development Goals (SDGs), the World Health Assembly (WHA), Roll Back Malaria (RBM) targets and in many other groups (WHO, 2014; Alemayehu et al., 2015).

In tropical and subtropical countries, malaria continues to play a leading role in causing morbidity and mortality. About $90 \%$ of the one million deaths resulting from malaria in the world occur in Africa. For example, in Central Africa sub region, malaria is transmitted by mosquito vector especially Anopheles gambie. Similarly, climate variability and change have aggravated morbidity and mortality resulting from malaria in most parts of Cameroon, particularly North West region. (Tchuinkam et al., 2010; Ndoforet al., 2013; Mbouna et al., 2019).

Malaria is endemic throughout Cameroon affecting almost $40 \%$ of its estimated 30 million people thus, constituting the first major cause of morbidity and mortality among the most vulnerable groups (children $<5$ years, pregnant women, people living with pre-existing medical conditions like HIV/AIDS and people living in abject poverty (Ngum et al., 2010; Mbouna et al., 2019). For instance, more than 50 percent of malaria morbidity occur in children below five years. Cameroon's burden of malaria continues to rise because its poverty and epidemiological profiles are not properly articulated in the national strategic plan, as they are mostly health facilities oriented and not well tailored to meet local needs. As a results those in need are left behind. With regards to the epidemiological profile and the transmission pattern, the western high plateau section is an endemic and perennial zone of consistent malaria transmission of between seven to twelve months (Ngum et al., 2010; Nkuo-Akenji et al., 2006; Tchuinkam et al., 2010; Tonui et al., 2008; Mbouna et al., 2019). This zone has a typical tropical climate with a prolonged rainy season of about eight months and a dry season of about four months. Mean yearly rainfall varies between $1500 \mathrm{~mm}$ to more than $2000 \mathrm{~mm}$ while temperatures average annual temperatures varies between $15^{\circ} \mathrm{C}$ to $25^{\circ} \mathrm{C}$.

Malaria prevalence in this zone is stable throughout the year but sometimes reduced due to the moderating effects of altitude. The major malaria parasites here include P. falciparum, P. 
Malariae and P. ovale with P. falciparum causing up to about 96 percent of malaria cases. The dominant vector here is Anopheles gambiae and it is highly resistant to Dichlorodiphenyltrichloroethane (DDT) spray (Ngum et al., 2010), which is a well-known spray against malaria vector. This zone harbors the entire Kumbo central Sub Division in the North West Region of Cameroon. Although the state and other partners have deployed the national malaria control programme (NMCP) to help curb the disease, malaria burden has remained unchanged over the past decades, leaving malaria services and commodities significantly low, thus, covering just a small percentage of the target coverage area.

High rates of malaria prevalence in the highlands of tropical Africa, e.g. Cameroon is a great call for concern, considering that highland areas are characterized by cooler weather conditions - a deterrent to malaria spreading vectors (Nkuo-Akenji et al., 2006; Tchuinkam et al., 2010; Tonui et al., 2008; Antonio-Nkondjio et al., 2019). For example, the North-West Region of Cameroon happens to be one of such highland areas with a significantly high rate of malaria morbidity and mortality despite its high altitude of more than 1.500 meters above the sea level, which calls for further research. Within this context, the study sought to investigate the relationship between climate variability and malaria emergence in North West Cameroon, with the intention to assess the degree of variability in climate parameters, to examine the role of this climate variability on the emergence of malaria, to analyze the impacts of climate variability driven malaria emergence on the population and finally, to identify the adaptation measures taken up by the population and the efficacy of these measures in curbing the population's vulnerability to malaria.

\subsection{Conceptual Framework of Climate Variability and Malaria Emergence}

The conceptual framework for this study focuses on climate variability and malaria emergence (Figure 1). According to the IPCC, climate variability refers to variations in the mean state and other statistics (such as standard deviations, the occurrence of extremes, etc.) of the climate on all spatial and temporal scales beyond that of individual weather events (IPCC, 2018). Variability may be due to natural internal processes within the climate system (internal variability), or to variations in natural or anthropogenic external forcing (external variability) (Huber and Gulledge, 2011). Malaria is a deadly disease caused by plasmodium parasites which are spread to humans through the bite of infected female anopheles mosquitoes known as malaria vectors (WHO, 2019). In this study, it is hypothesized that increasing variability in climate has led to warmer and humid conditions which favors the spread of vectors (mosquitoes) thereby triggering the emergence of malaria. Considering that North West Cameroon is a predominantly highland region, the weather and climatic conditions by default should be cool and dry. On the contrary, in the past few decades, weather and climatic conditions have radically changed, turning the predominantly highland North West region of Cameroon into a fertile ground for vectors (mosquitoes) which spread malaria. 


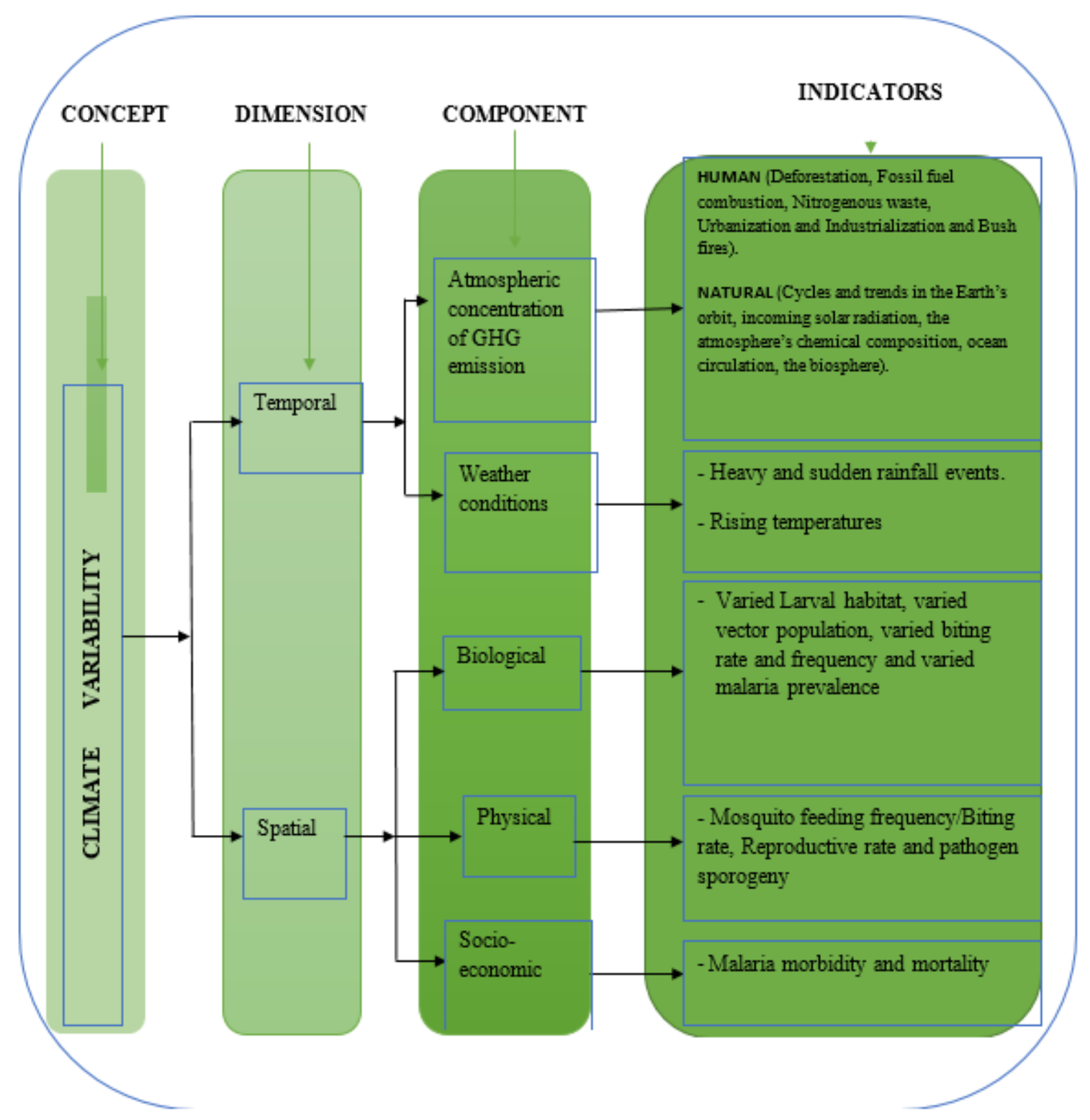

Figure 1. Conceptual framework of Climate Variability and Malaria Emergence

\subsection{Theoretical Framework}

The theoretical framework for this study centers on the MARA (Mapping Malaria Risk in Africa) Model. This model looks at temperature and rainfall as the major climatic elements that influence the variability of malaria morbidity and mortality. Particularly temperature is crucial in determining the proliferation rate of the anopheles' mosquitoes and the maturation rate of the pathogen (Craig et al. 1999). The optimal temperature ranges for the survival of the female anopheles' mosquito which spreads malaria lies between $20^{\circ} \mathrm{C}$ to $30^{\circ} \mathrm{C}$ (Craig et al. 1999). It has been demonstrated that "an average monthly humidity of below $55 \%$ and above $80 \%$ shortens the lifespan of the mosquito and malaria transmission". (Craig et al., 1999; Bhattacharya et al., 2006). Thus, rainfall and temperature significantly influence the availability and habitats suitability for the vector, specifically, the female anopheles mosquito 
(Wandiga et al., 2006).

\section{Materials and Methods}

\subsection{Location of the Studied Site}

The study was conducted in North West Cameroon, precisely in Kumbo Central Sub-Division (KCSD) (Figure 2), at $110 \mathrm{~km}$ North of Bamenda town. It has a total population of about 127,538 inhabitants, covering a surface area of $630 \mathrm{Km}^{2}$ with an average population density of 250 persons per $\mathrm{km}^{2}$ based on the 2018 estimates (SCORECARD, 2018). This area lies between Latitude $6^{\circ} 7^{\prime}$ and $6^{\circ} 24^{\prime} \mathrm{N}$, Longitude $10^{\circ} 35^{\prime}$ and $10^{\circ} 54^{\prime}$ E. Its altitude is about 1800 meters above sea level.

The climate of Kumbo is characterized by a marked dry and wet season, which is similar to the Tropical savanna type that prevails in the whole Grassland region of West Africa. Two major air masses, the wet monsoon and Harmattan are characteristic of the alternate dry and wet seasons in this region (Mbouna et al., 2019). Following the apparent movement of the sun north and south of the Equator, the monsoon air mass blows over West Africa from March to early November pushing the Inter-Tropical Front (ITF) to the North to bring about wet conditions. From November, the Harmattan, dry dusty and conditional pushes the ITF as far as to the West African coast to bring dry and cold conditions in this region. Thus, the different lengths of the two seasons in this region depend on the arrival and departure of the ITF. This equally determines the period and duration of mosquitoe development and consequently, the spread of malaria parasite. Besides the alternating effects of the ITF, micro-climate imposed by relief can always occur. Rainfall has been varying over the years in the study area. The hilly regions of Kumbo are often foggy and misty, receiving about 2300 $\mathrm{mm}$ of rainfall annually, while the lowlands or valleys receive about $1500-2000 \mathrm{~mm}$ of rainfall. The seasonal rhythm of rainfall intervenes on the level of the rivers and on the existence of most streams. During the dry season (Mid October to Mid-March), the volume of rivers falls and most streams dry off leaving the valleys with shallow pools of water which become conducive environments for mosquitoes that causes malaria. This situation is reversed in the rainy season (Mid-March to Mid-October), when existing rivers increase their volumes and dry river valleys become marshy areas. However, the variability in climate in recent years has altered season pattern, as rains sometimes come before mid-March and go away towards the end of October.

The mean annual temperatures vary between $22^{\circ} \mathrm{C}$ and $25^{\circ} \mathrm{C}$. The high altitudes zones have an average maximum temperature of $19-22.5^{\circ} \mathrm{C}$ and a minimum of $13^{\circ}-15.6^{\circ} \mathrm{C}$, while low altitudes zones have a maximum of $22.5^{\circ} \mathrm{C}$ and a minimum average of $20^{\circ} \mathrm{C}$. This temperature threshold favors the development and growth of mosquitoes that transmit malaria parasite to humans, since it falls within the range given by Githeko (2009), who said the development rate of mosquito larvae is temperature-dependent such that below $16{ }^{\circ} \mathrm{C}$, the development of Anopheles gambie stops and below $14{ }^{\circ} \mathrm{C}$ they die.

Bui division as a whole and KCSD in particular are found within the Western Highlands Ecological Zone (WHEZ), within a plateau relief. It is generally dominated by interfluves, thus, hilly with some inhabited areas above 2000 meters. These undulating hills are often separated from each other by deep valleys drained by fast moving streams that take their rise 


\section{Macrothink}

from some nearby watershed highlands. It is made up of three major relief units. The Western and Eastern Regions are highlands with altitude above 2000 m, such as in Kitiwum and Kingomen. The central region which makes up a plateau of about $1700 \mathrm{~m}$ to $2000 \mathrm{~m}$, in Berlem, Tadu, Shukai and the South Eastern parts extends up to River Bui, occupying the lowest points of below $1700 \mathrm{~m}$.

Bui division (with Kumbo as headquarter) is drained by some major rivers and their tributaries. River Bui (from where Bui Division takes its name) constitute the major drainage basin. The tributaries (streams and rivers) that constitute this drainage basin include River Meluf, River Kiyan, River Takijah, River Tadu, River Takui, River Maireen and River Kizaan. Most of these rivers, take their rise from Mount Oku in Oku Sub-Division, which is considered as the watershed of the entire Bui Division (Tume et al., 2019).

The vegetation cover in Kumbo is dominantly the tropical savannah types, with remnants of swampy (raffia palms, ferns, moss and various creeping plants), grassy (Hyparrhenia) and the Sporobolus or kikuyu grass) and gallery vegetation, which is gradually being transformed by the population for their numerous activities and services. Swamps serve as breeding grounds for mosquitoes while the gallery and grassland vegetation serves as their habitat.

The city center is built on three distinct interfluves. These built-up areas extend to the valleys. majority of households in Kumbo especially along valleys are poorly constructed, thus facilitating human-mosquito interaction. Most household and commercial refuse within the quarter is dumped around the surrounding yards which harbor mosquitoes.

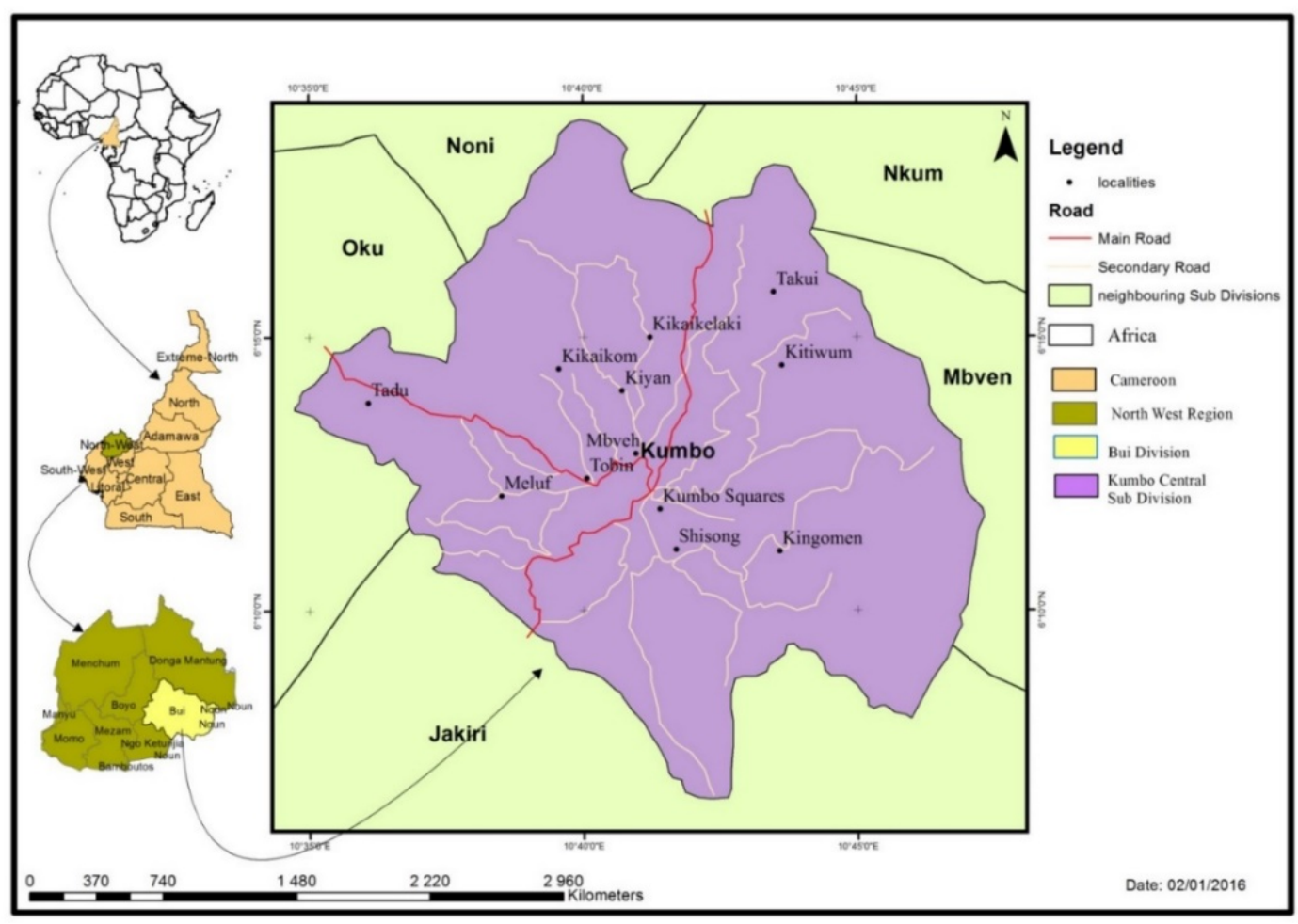

Figure 2. Map of Kumbo Central Sub Division in the North West region of Cameroon 


\section{Macrothink \\ International Journal of Global Sustainability \\ ISSN 1937-7924 2020, Vol. 4, No. 1}

\subsection{Data Collection and Analysis}

\subsubsection{Data Collection}

Primary data were collected using, researcher and participant's observations, interviews (with the Lord Major and Fon's representatives), semi structured questionnaires, recording sheets and cameras. The questionnaire was administered in seven main quarters/villages (Mbveh, Kumbo Squares, Tobin, Meluf, Kikaikon (K3), Kikaikelaki (K4), and Bamkikai) and seven health care units that had been in existence for at least 5 years(Banso Baptist Hospital (BBH), Saint Elizabeth Catholic General Hospital Shisong, Kitiwum Integrated Health center, Catholic Health Center Kingomen, Cameroon Baptist Convention (CBC) Health Center Bamdzeng, Kumbo Urban Integrated Health Center (KUIHC) and Centre Médical d'Arrondissement (CMA). The quarters were purposefully chosen based on the fact that their population was the most vulnerable to malaria, following reports from the different health care units and governmental and non-governmental organizations working within the health sector (SCORECARD, 2018). The number of questionnaires administered in each quarter was not consistent because of the variation in population structure (See Table 1). The questionnaire was distributed to the general public (69), patients and health personnel (84), and traditional healers (11). Of the 200 questionnaire distributed, a total of 164 individuals responded (see Table 1, Table 2 and Table 3 ).

Table 1. Number of Questionnaires administered to the general public in different quarters

\begin{tabular}{llll}
\hline No. & Quarter & Number of questionnaires & Representative percentage (\%) \\
\cline { 2 - 4 } 1 & Mbveh & 17 & 24.63 \\
2 & Kumbo town & 14 & 20.28 \\
3 & Tobin & 9 & 13.04 \\
4 & Meluf & 8 & 11.59 \\
5 & K3 & 9 & 13.04 \\
6 & K4 & 6 & 8.69 \\
7 & Bamkikai & 6 & 8.69 \\
& Total & $\mathbf{6 9}$ & $\mathbf{1 0 0}$ \\
\hline
\end{tabular}

Table 2. Number of questionnaires administered in different Health Units

\begin{tabular}{lllll}
\hline No. & Health Unit & Number of questionnaires & $\begin{array}{l}\text { Representative } \\
\text { (\%) }\end{array}$ \\
\hline 1 & B.B.H & 30 & 35.7 & percentage \\
2 & Saint $\quad$ Elizabeth & 37 & 44 & \\
& $\begin{array}{l}\text { Catholic General } \\
\end{array}$ & & \\
3 & Hospital Shisong & & \\
\hline
\end{tabular}




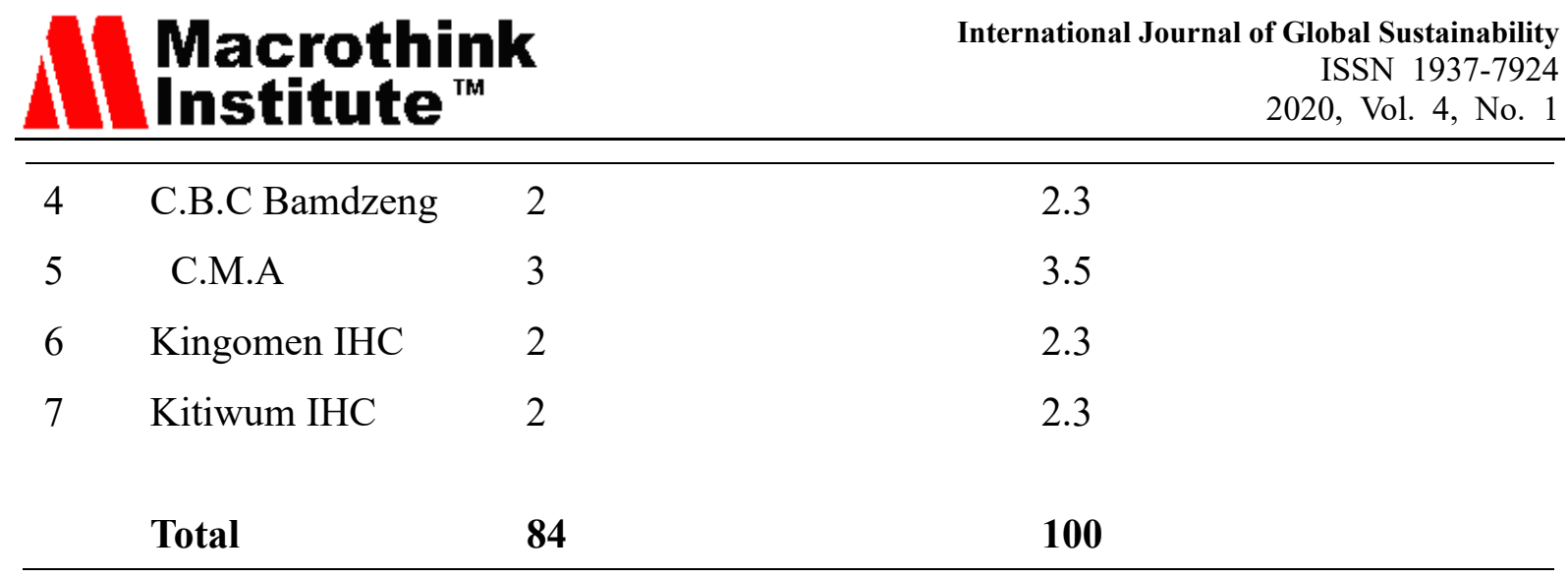

Table 3. Number of questionnaires administered to traditional healers in different quarters

\begin{tabular}{llll}
\hline No. & Quarter & Number of questionnaires & $\begin{array}{l}\text { Representative percentage } \\
(\mathbf{\%})\end{array}$ \\
\hline 1 & Mbveh & 2 & 18.18 \\
2 & Kumbo town & 1 & 9.09 \\
4 & Meluf & 2 & 18.18 \\
5 & K3 & 1 & 9.09 \\
6 & K4 & 2 & 18.18 \\
7 & Bamkikai & 3 & 27.27 \\
& Total & $\mathbf{1 1}$ & $\mathbf{1 0 0}$ \\
\hline
\end{tabular}

Respondents were randomly selected in the different quarters to obtain detailed information on their perception about climate variability and the emergence of malaria. Direct observations were made in the field and photographs of some shabby quarters and marked effects of climate variability were taken with a digital camera.

Secondary data were collected from hospitals, meteorological stations and library research. Other information was retrieved from the internet and offices (which are mostly gotten from documented data sources and archives). Malaria data were collected from statistical offices in the aforementioned hospitals. Meteorological data (temperature and rainfall) were collected from Saint Elizabeth Catholic General Hospital Shisong, and from the Divisional Delegation of Agriculture and from the Delegation of Transport for Kumbo. Both malaria and meteorological data from the years 2007 to 2014 and 1998-2014 respectively, were collected. The data collection procedure for this study adopts other related studies conducted in north western Cameroon (Awazi \& Tchamba, 2018; Awazi et al., 2019; Tume, 2019; and Tume et al., 2019).

\subsubsection{Data Analysis}

The collected data were organized, entered into the computer and datasets were developed. Descriptive and inferential statistics were used to analyze data under Microsoft office excel 2016 and SPSS v20 software. 


\subsection{Ethical Consideration}

In order to stick to the ethics related to human health research, an application for ethical consideration was submitted to Dschang School of Letters and Social Sciences. This document, entitled "Ethical consideration for a Masters research" was approved by the committee in charge of research evaluation and validation. It contained information related to the objective (s) of the study and the duration of the survey. It also had information showing that the authors will uphold to ethical behavior in terms of confidentiality and anonymity throughout the research work and would not in any way expose the identity of those involved in the research process to the general public. It also made it clear that, every health data (hard or soft copy, words, video and photograph) collected from the health units and from other participants would be handled with care. This document was under reviewed for two and a half weeks and the committee in charge finally granted permission for the research to be conducted.

\section{Results and Discussion}

\subsection{Variability in Climate Elements}

In this study, climate variability is considered as an alternation in the mean state and other statistics of the climate on all spatio-temporal dimensions outside that of specific weather occurrences (IPCC, 2018).

\subsubsection{Rainfall Variability}

Rainfall variability is one of the most important element and indicator of climatic variability in Kumbo. The nature of rainfall events, its pattern of distribution in time and space, the duration and intensity of occurrence, the monthly, yearly and seasonal patterns of distribution has been under fluctuations in the past sixteen years (Figure 3). This study found significant levels of variability in the quantity of rainfall around the mean (average) in Kumbo from 1998 to 2014. The average annual rainfall during this lag of time stood at $2043.96 \mathrm{~mm}$ with the wettest year (2007) recording an annual rainfall of $2268.6 \mathrm{~mm}$ while the least rainfall was recorded in 2011 with an amount of $1693.3 \mathrm{~mm}$. It was observed that there is a steady fluctation of annual average rainfall around the mean from 1998 to 2009, and a variation below the mean from 2010 to 2014. This shows that there is a trend towards decreasing annual rainfall after the year 2010, the observed modifications of annual rainfall could thus influence habitats parameters and consequently increase the populations of plasmodium vector as well as other mosquitoes.

Kumbo Central Sub-Division generally has two main seasons, the rainy season that begins in mid-March and ends in mid-October and a dry season that stretches from mid-October to mid-March. In the past years, this seasonal pattern has experienced some fluctuations, as rain sometimes begin before the $10^{\text {th }}$ of March or in April instead of mid-March. This is evident in the years 2010 to 2014 where the rainy season stretched from February to November. However, yearly totals from 2010 to 2014 still remained low compared to the rest of the years which support previous findings (Sunjo et al., 2012; Tume, 2019; and Tume et al (2019). 


\section{Ml Macrothink}

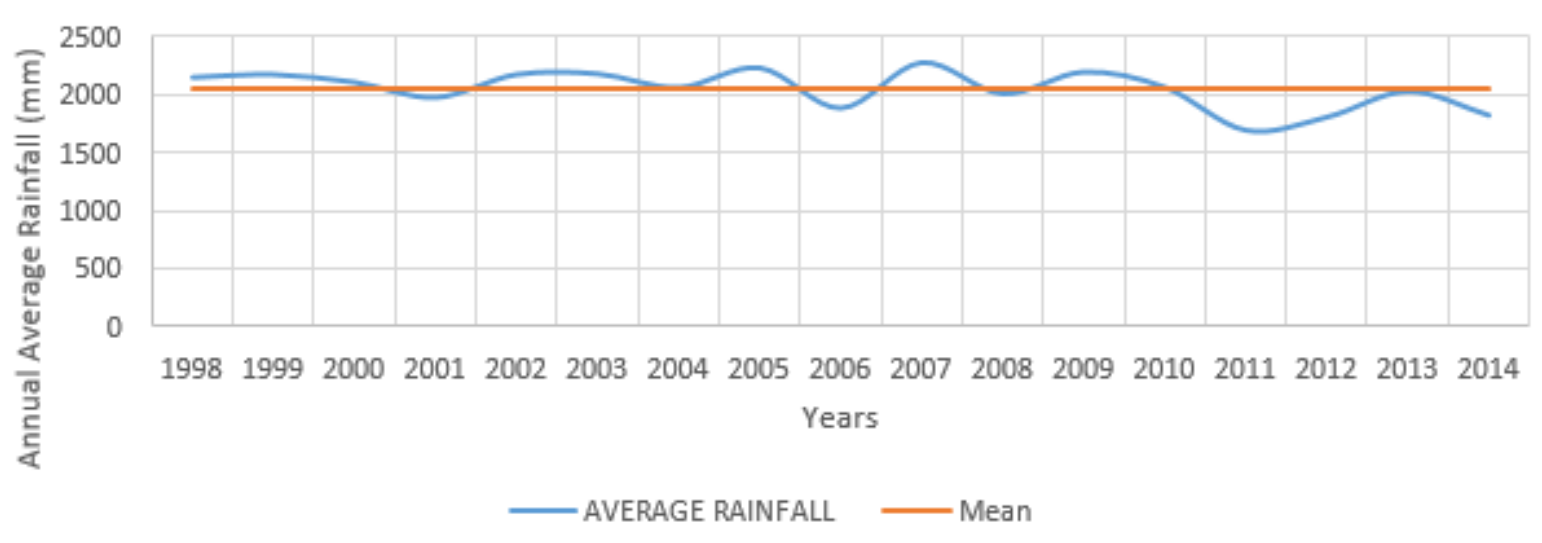

Figure 3. Variability of annual average rainfall around the mean

With regards to monthly variability, the highest average monthly rainfall in Kumbo Central Sub Division was usually recorded in the months of July, August and September with average monthly rainfall figures of $468 \mathrm{~mm}, 261.3 \mathrm{~mm}$ and $255.8 \mathrm{~mm}$ respectively for the past sixteen years, while the lowest is registered in December and January with the least quantities of average rainfall of $0.4 \mathrm{~mm}$ and $3.8 \mathrm{~mm}$ respectively. However, in recent years (2004 to 2014), there has been significant variations and changes in this monthly pattern of rainfall. To better study monthly rainfall variability, the study presented monthly rainfall for the wettest year in (2007) and the driest year in (2011). In the wettest year, July recorded the highest monthly rainfall $(468.7 \mathrm{~mm})$ while in the driest year, August recorded the highest monthly rainfall (306.6 mm). July and August falls in the heart of the rainy season while no rainfall was recorded in December and January which falls in the heart of dry season. These results support previous research which found that July and August have been the wettest months (Tume, 2019; Tume et al., 2019).

From the spatio-temporal standpoint, rainfall varied significantly in the sixteen years under study. More than $70 \%$ of the respondents confirmed that although rainfall pattern had not changed too much, rainfall intensity varies from one village to the other. Other authors have equally reported high levels of variability in rainfall (Gur et al., 2015; Innocent et al., 2016; Kimengsi and Botanga, 2017; Awazi and Tchamba, 2018; and Awazi et al., 2019).

\subsubsection{Temperature Variability}

In Kumbo Central Sub-Division, temperature has been fluctuating in the past decades. These fluctuations seriously impact human health. Although average annual temperature did not deviate too significantly from the mean, the results obtained insinuated a general inclination towards warming for Kumbo. Figure 4 shows the variation of annual average temperature around the mean from 1998-2014. 2005 recorded the highest temperature $\left(35.58{ }^{\circ} \mathrm{C}\right)$ while 2014 recorded the lowest temperature (19.07) through out the surveillance period. Thus, both 2005 and 2014 were considered as the hottest and coldest years respectively. The mean temperature being $24.56^{\circ} \mathrm{C}$, Kongnso (2010), Sunjo et al (2012) and Tume et al (2019) have all reported close to similar findings in studies conducted in and around Kumbo Central Sub-Division, North West region of Cameroon. 


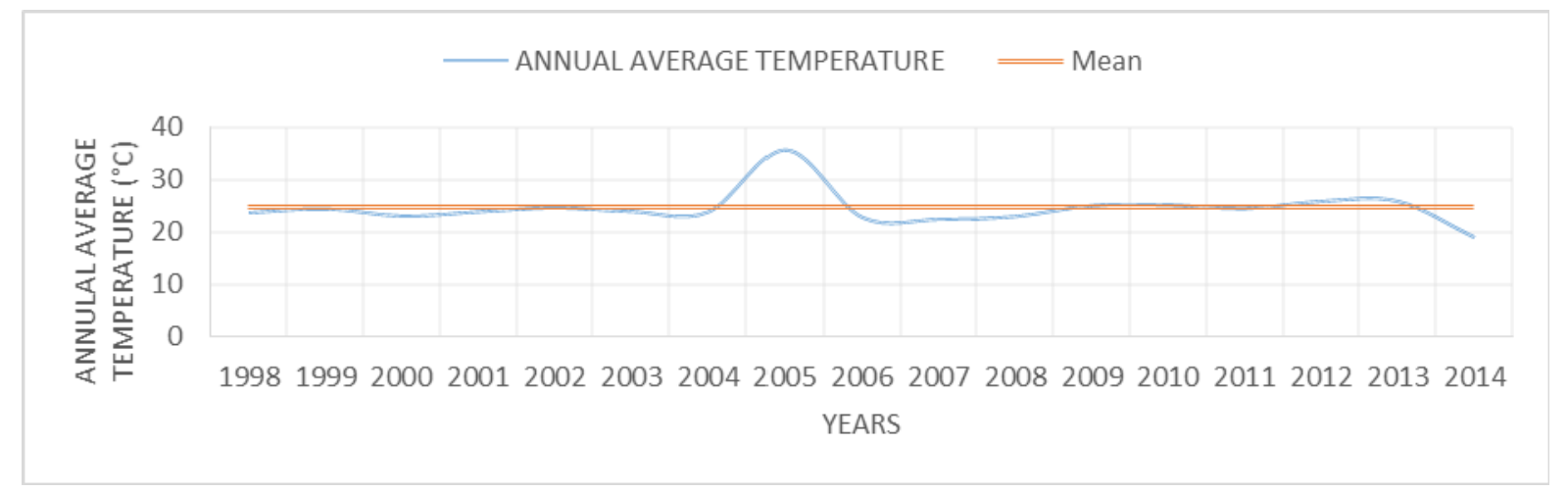

Figure 4. Fluctuation of annual average temperature around the mean

Temperatures fluctuated significantly from season to season and from one month to another in the study area. The highest average temperature was recorded in the months of December and February with means of $36.5^{\circ} \mathrm{C}$ and $36.9^{\circ} \mathrm{C}$ respectively. These two months fall within the heart of the dry season. The lowest average temperature was recorded in the months of July, August and September with means of $18.3{ }^{\circ} \mathrm{C}, 18.6^{\circ} \mathrm{C}$ and $18.4{ }^{\circ} \mathrm{C}$ respectively. These months fall within the heart of the rainy season. To better analyze average monthly/ seasonal temperature for Kumbo Central Sub Division, the years 2005, 2007, 2012, 2013 and 2014 were studied because they represented years with temperature extremes. The years 2005, 2012 and 2013 registered very high monthly temperatures, with 2005 recording the highest. Conversely, 2007 and 2014 registered very low monthly temperatures, with 2014 recording the lowest. In 2005 (hottest year), February recorded the highest average monthly temperature of $36.9^{\circ} \mathrm{C}$ with October registering $34.6^{\circ} \mathrm{C}$ as the lowest temperature of that year. Conversely, 2014 which recorded the coldest temperature had its highest temperature in the month of April $\left(20.85^{\circ} \mathrm{C}\right)$ and its lowest temperature in July, November and December $\left(18.3^{\circ} \mathrm{C}\right)$. As reported by other authors in studies undertaken in north western Cameroon, seasonal and monthly temperatures have been fluctuating greatly in recent years (Awazi and Tchamba, 2018; Awazi et al., 2019; Tume, 2019; and Tume et al., 2019).

Interviews with respondents indicated that households found in low-lying areas complained of too much heat where as those uphill complained of too much cold. This disparity can be explained through the exchange of valley winds moving up hill (anabatic) and local downward motion of cool air (katabatic) that usually play a significant role in the modification of climate parameters notably temperature. A similar scenario has been reported by other researchers in studies conducted across the tropics (Mcsweeney et al., 2008; and Capstick et al., 2014).

\subsection{Role of Climate Variability in Malaria Prevalence}

For this study, only two climatic indicators have been considered as most important in influencing the malaria epidemic and its pattern in the study area. This includes temperature and rainfall in lower (Bui valleys) and higher (Kitiwum) altitudes. Many diseases including malaria prevalence are closely associated to climatic conditions (Wuyi et al., 2010; Wua et al., 2016; Metcalf, 2017). Temperature and rainfall modifications through time can help in explaining the dynamism of malaria vectors and parasites through space and time. 


\subsubsection{Yearly Climate Variability and Malaria Morbidity}

Annual rainfall and temperature variability play a key role in influencing malaria prevalence. The influence of these climate parameters are observed in Figure 5a and b.

\subsubsection{Annual average rainfall variability and malaria morbidity}

The variability pattern of annual average rainfall and malaria morbidity did not show any clear or positive relationship throughout the surveillance period (Figure 5a). However, low malaria morbidity was found to occur during high annual rainfall as shown by the years 2007 and 2009. This was contrary to the findings of Nkuo-Akenji et al (2006) whose study conducted around the slopes of Mount Cameroon in the South West Region of Cameroon found that malaria prevalence is stronger during periods of higher rainfall than periods of lower rainfall. Another trend was also observed from 2011 to 2014 where persistent low quantities of rainfall was associated with high malaria morbidity which could be attributed to the existence of many stagnant water sources resulting from sudden copious downpours. This equally goes contrary to the findings of Nkuo-Akenji et al (2006). Although, more than $80 \%$ of inhabitants were of the opinion that malaria affects children between 0-5 years and pregnant women more than the rest of the population, the reverse was true for majority of nurses in Hospitals and Health centers who explained that morbidity is very rampant in the active age groups. Studies conducted by Beier et al (2008), Bowen (2013), Pemunta (2013), Peter et al (2014), and Givemore et al (2014) across different parts of the tropics have demonstrated that perceptions vary on the effects of malaria on different age groups.

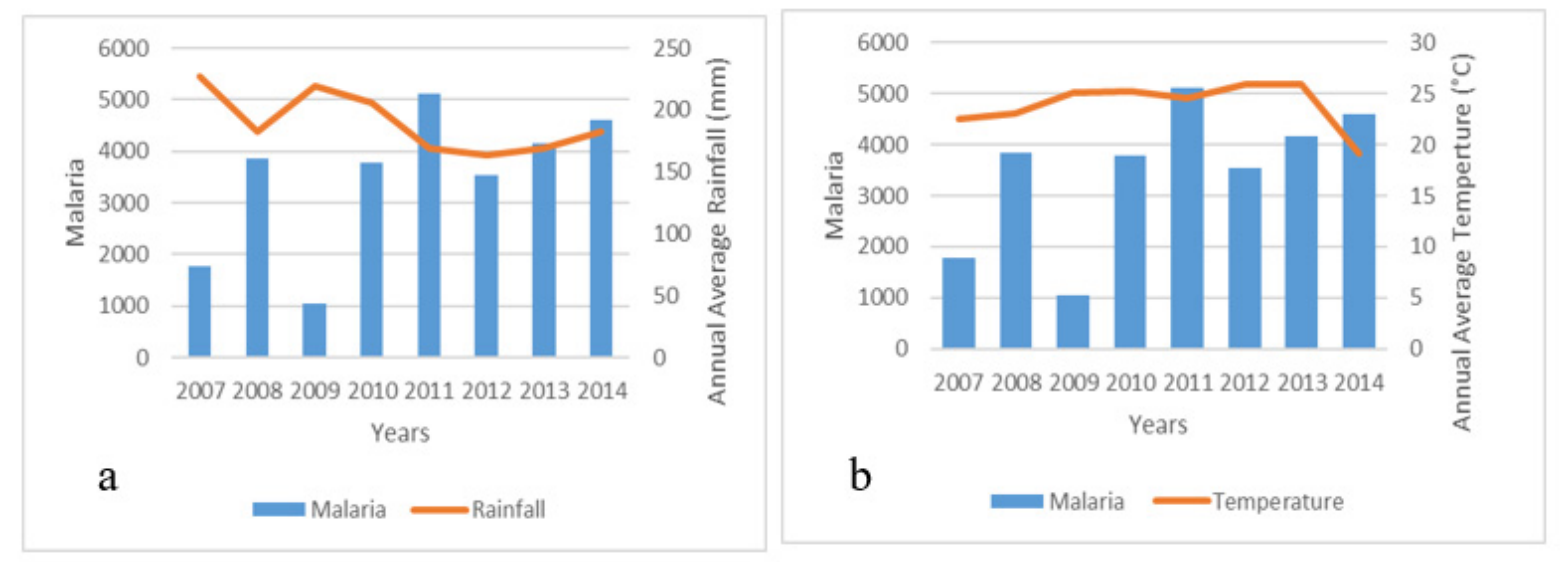

Figure 5. Yearly Climate variability and malaria morbidity

\subsubsection{Annual Average Temperature Variability and Malaria Morbidity}

It was found that annual average temperature and malaria morbidity remained very inconsistent throughout the surveillance period (Figure 5b). High morbidity was recorded during the period between 2011 and 2014. In the years 2011 (5115), 2013 (4165) and 2014 (4600). The lowest morbidity was recorded in the year 2007 (1780) and 2009 (1049). This showed that there was no clear relationship between annual average temperature and malaria morbidity. The year 2011 which recorded the highest peak of malaria, recorded an annual average temperature of $24.54{ }^{\circ} \mathrm{C}$. This was followed by the years 2013 and 2014 with a 
morbidity of 4600 and 4165 respectively. However, the years 2012 and 2013 which recorded the highest annual temperatures $\left(25.92^{\circ} \mathrm{C}\right.$ and $\left.25.90^{\circ} \mathrm{C}\right)$ recorded 3435 and 4165 cases of malaria morbidity respectively. In all the years, annual temperatures remained significantly high to maintain high morbidity as observed by Githeko (2009), but higher variations in malaria prevalence observed throughout the year may also be attributed to other factors amongst which is rainfall as reported by other studies conducted across the tropics (Bouma and van der Kaay, 1995; Durrheim et al., 1998; Gubler et al., 2001; and McNeil, 2008).

\subsubsection{Correlation Between Yearly Malaria Morbidity and Climate Parameters}

The correlation between yearly malaria morbidity and annual average rainfall was further tested using Spearman Correlation. The approximate Significance obtained was 0.029, which is significant at 0.05 probability level $(\boldsymbol{P}=0.05)$. This results implies that there is a strong inverse relationship between yearly malaria morbidity and annual average rainfall. The results of Bhattacharya et al. (2006) in a study conducted in the localities of Shaurashtra and Kutch (India), also showed a negegative correlation between rainfall and malaria morbidity as high rainfall resulted in low malaria prevalence.

Annual average temperature and yearly malaria morbidity was equally tested using Spearman Correlation statistical test. The approximate Significance obtained was 0.74 , which is less than 0.10 probability level $(P<0.10)$. This result indicated that there is a positive correlation between yearly malaria morbidity and annual average temperature.

The positive correlation $(\mathrm{p}<0.10)$ between annual temperature and malaria morbidity in Kumbo show that monthly temperature seems to be one of the driving forces behind the high prevalence rate of malaria in Kumbo. This is corroborated by Githeko Andrew (2009) who observed that "the development rate of mosquito larvae is temperature-dependent such that below $16{ }^{\circ} \mathrm{C}$, the development of Anopheles gambiae stops and below $14{ }^{\circ} \mathrm{C}$ they die. Thus once they become adults, the rate at which they feed is again temperature-dependent such that at $17^{\circ} \mathrm{C}$, the female mosquito (Anopheles gambiae) feeds on human blood every 4 days while at $25^{\circ} \mathrm{C}$, they need blood meal every 2 days". Nevertheless, this correlation is relatively weak in the studied area implying that other individual factors or combination of factors might better explain malaria morbidity in that area.

\subsubsection{Monthly / Seasonal Variability and Malaria Morbidity}

To better analyze monthly/seasonal variability and malaria morbidity, the years 2011 and 2014 were selected because these years registered the highest malaria morbidity cases of 5115 and 4600 respectively.

In 2011 the monthly/seasonal variability of rainfall showed high rainfall $(>150 \mathrm{~mm})$ from April to October that were associated with low malaria morbidity (Figure 6a). Conversely, morbidity is higher from November to March with very low monthly rainfall $(<70 \mathrm{~mm})$. The months of November, December, January and February recorded higher cases of morbidity during the years. Highest number of malaria morbidity were obtained in February and March, with 672 and 627 cases registered respectively. These months cover the entire dry season in Kumbo. The month of July at the heart of the rainy season registered the least cases of malaria morbidity with 265 cases.

In 2014, although there was no clear trend in the monthly variation of rainfall and malaria 
morbidity, it was observed (Figure $6 \mathrm{~b}$ ) that more cases of morbidity are registered within the first 4 months and the last 3 months of the year (dry season) when there is little or no rainfall $(<235 \mathrm{~mm})$. However, fewer cases of morbidity are registered within the months of August, September and October (rainy season) when there is abundant rainfall $(>230 \mathrm{~mm})$. Furthermore, in 2014, more cases of malaria morbidity were registered during the months of May (533), July (450) and November (619). Thus, it is noticed that the transitional months i.e. rainy season to dry season or dry season to rainy season were characterized by higher prevalence rates of malaria. This could be attributed to the warm and damp nature of these months when compared with the other months, these conditions are probably more favorable to the development of vectors and plasmodium larvae. This is true according to Wandiga et al. (2006), who claims that malaria epidemics occur about two months after the peak of rainfall. It was noted that while rainfall has more defined seasons, malaria remains high throughout the year, an indication that the impacts of variability of rainfall on malaria is not the only factor that maintained the high prevelence of malaria in the human population. This clearly indicates that other factors could be playing a role in the high rate of prevalence of malaria morbidity in Kumbo Central Sub Division. Campbell-Lendrum et al. (2003), Nkuo-Akenji et al. (2006), CDC (2007), Olson et al.(2009), Protopopoff et al. (2009) have equally reported that several drivers such as social, economic and environmental factors influence malaria prevalence in the tropics.

On the monthly/seasonal temperature variability and malaria in 2011 (Figure 6a), both variables tended to follow the same trend, except for May and June where high temperatures were accompanied by relatively fewer cases of malaria. February and March which recorded temperatures of greater than $25^{\circ} \mathrm{C}$ equally registered higher morbidity values. Contrarily, from July to December with temperatures of less than $25^{\circ} \mathrm{C}$, low to moderate cases of morbidity were also registered. However, high morbidity throughout the year could be attributed to the corresponding high temperatures of more than $22^{\circ} \mathrm{C}$ or to the influence of factors other than temperature. This consistency between morbidity and temperature also accounted for the highest morbidity which gave 2011 the highest rate of malaria infection throughout the study period.

Monthly/seasonal variability of temperature and malaria in 2014 (Figure 6b) did not show a clear relationship. This explains why March and April which recorded high temperatures $\left(>20^{\circ} \mathrm{C}\right)$, registered moderate cases of malaria morbidity whereas May to December which recorded very low temperatures of between $18^{\circ} \mathrm{C}$ to $19^{\circ} \mathrm{C}$ registered one of the highest morbidity cases. This is an indication that many factors played a role in the emergence of malaria in Kumbo apart from temperature. However, the variability of environmental conditions within a given month might also be a crucial factor for the development of parasites and vectors. In that case, period of the month with highest temperature favored the prevalence of malaria.

Temperature remained however a crucial factor in determining the proliferation rate of the anopheles' mosquitoes and the maturation rate of the pathogen. For example, the lowest temperature for the development of $P$. falciparum is $18^{\circ} \mathrm{C}$, given that, as temperature declines, so does the development of malaria parasite for example, is 26 days at $20^{\circ} \mathrm{C}$ and only 13 days at $25^{\circ} \mathrm{C}$ (Ting and Ming, 2005; Bhattacharya et al., 2006). According to Craig et al. 


\section{Macrothink}

(1999), for most anopheles' vector species of malaria, the optimal temperature range for survival lies within $20^{\circ} \mathrm{C}$ to $30^{\circ} \mathrm{C}$.

In comparing the seasonal temperature changes with that of malaria morbidity in 2014, it was found that the monthly results appear to alternate in occurrence. The months of May, July and November had the lowest temperatures $\left(19.4^{\circ} \mathrm{C}, 18.3^{\circ} \mathrm{C}\right.$ and $\left.18.3^{\circ} \mathrm{C}\right)$ respectively, yet they registered the highest morbidity $(533,450$, and 619$)$ respectively.

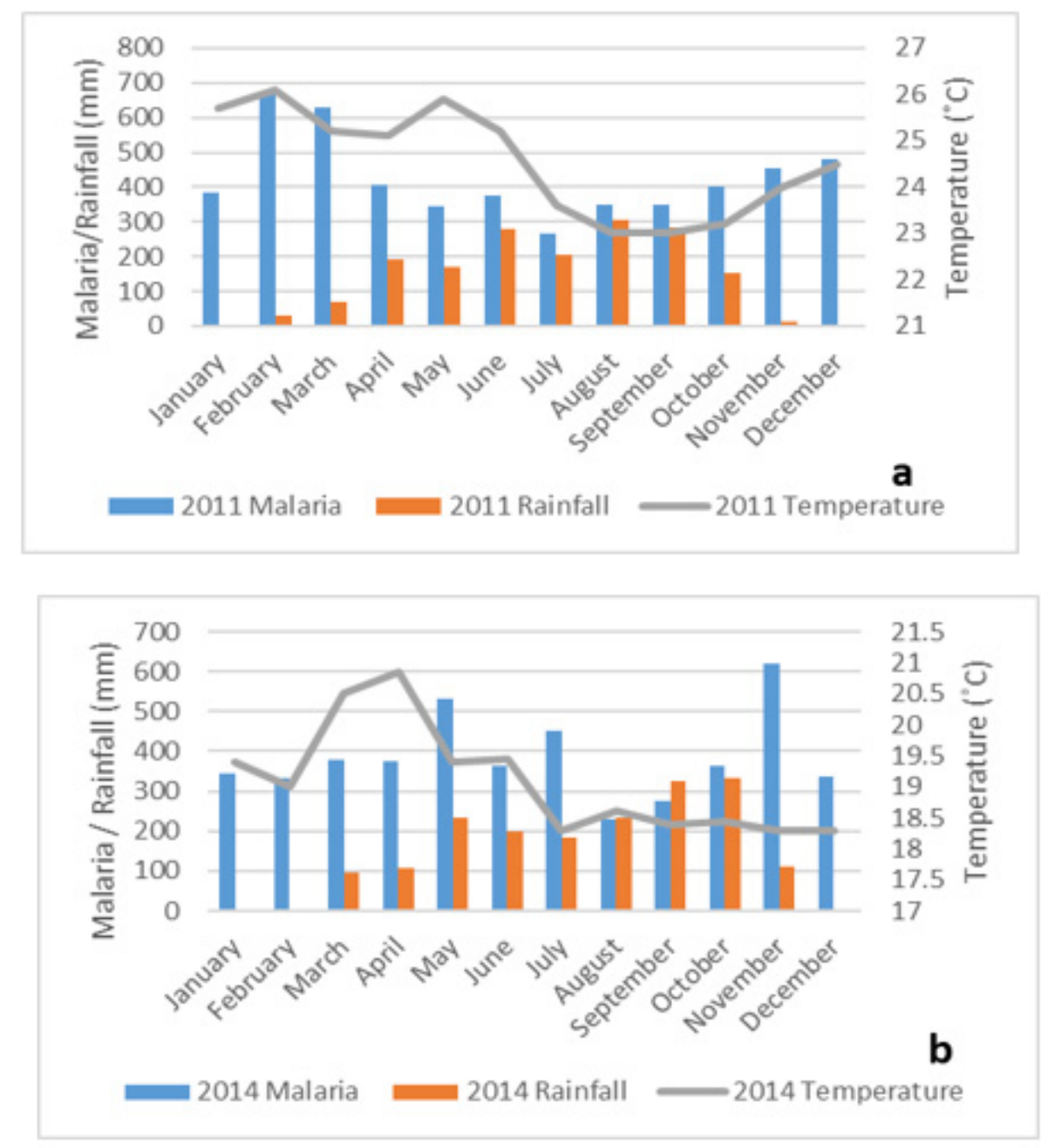

Figure 6. Average Monthly/ Seasonal climate variability and malaria morbidity 2011 and 2014

On the other hand, the months with the highest temperatures had very low morbidity. From the results, it can be seen that temperatures rose gradually from the heart of the dry season in January to their peak at the beginning of the rainy season in April and diminish slowly with the setting in of more rains till the beginning of the dry season. But it is the rains that are responsible for the provision of the suitable larval habitat because the habitat may be at its best immediately after the rains. Temperature remains optimal while there are plenty of the larval habitats. This leads to high vector population such that according to Wandiga et al. 
(2006), malaria escalates around two months after the rains, a time when the temperatures are relatively at their lowest, but optimal given that the optimal temperature ranges for both the vector and the parasite is between $15^{\circ} \mathrm{C}$ and $31^{\circ} \mathrm{C}$ (Campbell-Lendrum et al., 2003). In the same light $30^{\circ} \mathrm{C}-32^{\circ} \mathrm{C}$ is an ideal temperature for falciparum malaria (Ngarakana-Gwasira et al., 2016). The lowest temperature $\left(18.3^{\circ} \mathrm{C}\right)$ for Kumbo Central Sub Division therefore remains optimal and conducive for malaria transmission. Thus, the malaria prevalence rate did not completely follow the patterns of both temperature and rainfall, signaling that other factors may be responsible for the high rate of prevalence of malaria in Kumbo central sub-division as reported by other studies conducted across the tropics (Campbell-Lendrum et al., 2003; Nkuo-Akenji et al., 2006; CDC, 2007; Olson et al., 2009; Protopopoff et al., 2009; and Lehman, 2012).

\subsection{Impacts of Climate Variability Driven Malaria Prevalence on the Population}

\subsubsection{Malaria Mortality in Kumbo}

Based on statistics from Banso Baptist Hospital and Shisong Hospital, the main impact of climate variability on malaria transmission has been the increase in morbidity and mortality rates. Throughout the study period there has been a steady increase in malaria mortality even though, with a slide decrease in 2014 (Table 4). The highest mortality was registered in 2011 and 2013 for $\mathrm{BBH}$ and $\mathrm{SH}$ respectively. However, combining mortality cases for both hospitals, it is observed that mortality was highest in 2012.

Table 4. Total cases of malaria mortality from Banso Baptist Hospital (BBH) and Shisong Hospital ( $\mathrm{SH})$

\begin{tabular}{llllllllllllllll}
\hline $\mathbf{2 0 0 7}$ & & $\mathbf{2 0 0 8}$ & & $\mathbf{2 0 0 9}$ & & $\mathbf{2 0 1 0}$ & & $\mathbf{2 0 1 1}$ & & $\mathbf{2 0 1 2}$ & & $\mathbf{2 0 1 3}$ & & $\mathbf{2 0 1 4}$ \\
\hline BB & S & BB & S & BB & S & BB & S & BB & S & BB & S & BB & SH & BB & SH \\
H & H & H & H & H & H & H & H & H & H & H & H & H & & H & \\
15 & 0 & 14 & 0 & 4 & 0 & 15 & 0 & 17 & 7 & 14 & 15 & 16 & 9 & 6 & 1 \\
\hline
\end{tabular}

This study showed that the major impacts of high rates of malaria prevalence in Kumbo Central Sub Division were high rates of mortality. Studies conducted in Cameroon and other parts of the world concluded that malaria morbidity and mortality as well as other socio-economic losses have impoverish many societies, especially the most vulnerable population (children below 5 years, pregnant women, and people with pre-existing medical conditions) due to increase family expenditure, which gives way to poverty (Nkuo-Akenji et al., 2006; MINSANTE, 2015; Ngarakana-Gwasira et al., 2016). Furthermore, due to malaria infection, most patients are obliged to absent from school and work in order to get proper medical treatment. Similar findings have been reported by other authors in studies conducted across Cameroon, Africa and the world (Patzet al., 2002; Koenraadt et al., 2004; Lieshout et al., 2004; Nkuo-Akenji et al., 2006; and MINSANTE, 2015) demonstrating high rates of malaria prevalence have severe repercussions on the population.

\subsection{Coping Strategies for Climate Variation-malaria Trends in Kumbo}




\section{Macrothink Institute ${ }^{T M}$}

Respondents (inhabitants, hospital authorities and traditional healers) identified a plethora of coping strategies faced with high levels of malaria prevalence.

Long Lasting Insecticide Nets (LLINs) constituted 39.13\% of the strategies and there were often provided by the state. This seems to be the most significant coping strategy. This started effectively in 2010. Treatment constituted $11.59 \%$ of the coping strategies and usually given by hospitals, Health centers and traditional healers in Kumbo. Sensitization on its part constituted $8.70 \%$ of the coping strategies and usually carried out by public health authorities to malaria patients and pregnant women through seminars and workshops. Health Education which constituted $7.25 \%$ of strategies was mostly done by hospital authorities (nursing teachers, students) through quarter heads. Overall, $33.33 \%$ of the general population interviewed acknowledged the fact that coping strategies against malaria involved the integration of the above measures. Antonio-Nkondjio et al., (2019), concluded that LLINs and indoor residual spray (IRS) champions coping strategies for malaria control in Cameroon.

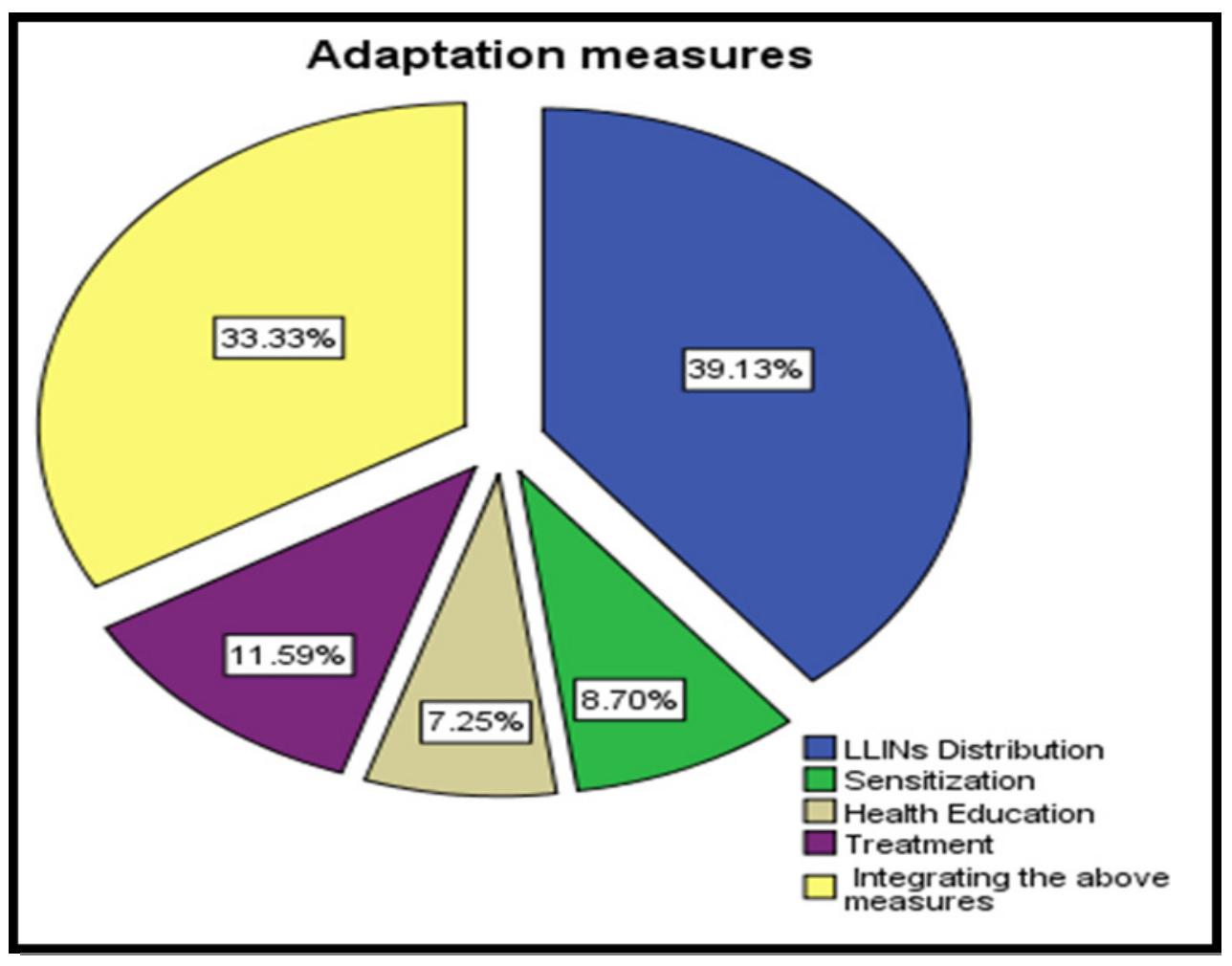

Figure 7. Adaptation measures against malaria transmission

Sensitization campaigns organized by governmental and non-governmental organizations have equally gone a long way to influence the population's coping strategies. For example, during the celebration of the $8^{\text {th }}$ World Malaria day on $27^{\text {th }}$ April 2015, Cameroon's Minister of Public Health, urged mothers to take their under-five year old children to the hospital as soon as they discover the first sign of malaria. According to him, there is no use for Cameroonians to show-case placards such as: "Roll back Malaria" "no more Malaria" and "No to the number one killer" if they cannot practically adapt to the use of treated mosquito nets which are free of charge. He also expressed his satisfaction to the drop of the rate of malaria infection in 


\section{Macrothink}

International Journal of Global Sustainability

ISSN 1937-7924

2020, Vol. 4, No. 1

Cameroon. In his speech, he said "the infection rate (Morbidity) experienced a drastic drop from $20 \%$ in 2010 to $10 \%$ in 2014 . Mortality rate has also dropped from $0.5 \%$ in 2014 to $0.2 \%$ in 2015". In order to intensify the fight against Malaria in the country, the Public Health boss announced the distribution of 12 million treated mosquito bed nets in the year 2015 and this distribution exercise effectively started in June 2015 across the country.

Some social groups in Kumbo Central Sub Division are trying to cope by planting eucalyptus trees in the flooded area that harbors mosquitoes. Some local people have accepted to live with the impacts of climate variability in the villages because they have no option, for example the elders. Others, especially the youth and a few able-bodied persons have decided to migrate either temporarily or permanently rather than suffer with the impacts of climate variability especially high prevalence rates of malaria. The major constraint mentioned in solving health impacts of climate variability included lack of and inadequate awareness, limited and poor health infrastructure including working facilities, poverty and limited numbers of health workers both at the district and the hospital level. Malakooti et al (1998); Sachs and Malaney (2002); Ngum et al (2010) and Ngarakana-Gwasira et al., (2016) in studies conducted in Cameroon, Africa and the world have all shown that the population takes to different coping strategies in order to mitigate the harsh repercussions of high rates of malaria prevalence.

\section{Conclusion and Recommendations}

Based on the findings of this study, it is clear that malaria is one of the major health problems affecting the population of Kumbo Central Sub Division. Several factors are responsible for the high rate of prevalence of malaria in the study area, one of which is climate variability. Variations in climate parameters (rainfall and temperature in particular) was found to be very significant. Rainfall and temperature variations worked differently towards influencing malaria prevalence in the study area. Temperature was a stronger determinant factor of malaria prevalence than rainfall, since high average monthly and annual temperature greatly corresponded with high malaria morbidity and mortality. It must however be noted that variability in climate parameters was not the only determinant of high rates of malaria prevalence in Kumbo Central Sub Division. Other determinants were involved in influencing malaria prevalence which have not been assessed in this study. Amongst the impacts of malaria prevalence on the population were high rates of morbidity and mortality and the main coping strategies employed by the population were the use of treated mosquito bed nets. From the findings of this study, it was demonstrated that climate variability plays a relatively significant role in influencing malaria prevalence in Kumbo Central Sub Division, North West region, Cameroon. However, not all aspects concerning the drivers and manifestations of malaria have been covered in this study. Therefore, the study recommends that the following should be done in order to adequately address the malaria palaver in Kumbo Central Sub Division in particular and the North West region of Cameroon in general: The government should integrate environmental phenomena like climate variability and change in the health policies, since the impacts of climate variability and change are cross-cutting. This suggest that, research should be carried out on the risk factors of malaria in the study area while addressing environmental, socio-economic and cultural variables, so as to have better insights on the root causes of malaria in Kumbo Central Sub Division. 


\section{Compliance with ethical standards}

Funding

This study received no external funding

Conflicts of interest

The authors declare no conflict of interest

\section{Acknowledgements}

We appreciate the respondents for their cooperation and for providing us with valuable information during the field surveys. Moreover, we are thankful to Assist. Prof. Dr. Timothy O. Iyendo, (Department of Architecture-European University of Lefke-Northern Cyprus) for guidance and for reviewing the manuscript.

\section{References}

Alemayehu M., Belay B., Abere M., Estifanos B., \& Michael C. Wimberly (2015). Seasonal associations of climatic drivers and malaria in the highlands of Ethiopia Parasites \& Vectors Sample.

Alexander, Z., \& Elena, C. (2017). Seasonal changes in precipitation extremes in Russia for the last several decades and their impact on vital activities of the human population. Geography, Environment, Sustainability, 10(4), 69-82. https://doi.org/10.24057/20719388-2017-10-4-69-82

Antonio-Nkondjio, C., Ndo, C., Njiokou, F., Bigoga, J. D., Awono-Ambene, P., Etang, J., ... \& Wondji, C. S. (2019). Review of malaria situation in Cameroon: technical viewpoint on challenges and prospects for disease elimination. Parasites \& vectors, 12(1), 501. https://doi.org/10.1186/s13071-019-3753-8

Awazi, N. P., \& Tchamba, N. M. (2018). Determinants of small-scale farmers' adaptation decision to climate variability and change in the North-West Region of Cameroon. Afr. $J$. Agric. Res, 13, 534-543. https://doi.org/10.5897/AJAR2018.12971

Awazi, N. P., Tchamba, N. M., \& Tabi, F. O. (2019). An assessment of adaptation options enhancing smallholder farmers' resilience to climate variability and change: Case of Mbengwi Central Sub-Division, North-West Region of Cameroon. Afr. J. Agric. Res, 14(6), 321-334.

Beier, C. J., Keating, J., Githure, I. J., Macdonald, M. B., Impoinvil, D. E., \& Novak, R. J. (2008). Integrated vector management for malaria control: license; Malaria Journal, 3-8. https://doi.org/10.1186/1475-2875-7-S1-S4

Bhattacharya, S., Sharma, C., \& Dhiman, R. C. (2006). Climate change and malaria in India. Current Science, 90(3), 354-361.

Bouma, M. J., \& van der Kaay, H. J. (1995). Epidemic Malaria in India's Thar Desert. Lancet, 373, 132-133. https://doi.org/10.1016/S0140-6736(95)92941-X

Bowen, H. L. (2013). Impact of a mass media campaign on bed net use in Cameroon. Malaria Journal, 12, 36. https://doi.org/10.1186/1475-2875-12-36

Campbell-Lendrum, D. H., Corvalan, C. F., \& Prüss Ustün, A. (2003). How much disease could climate change cause. Climate change and human health: risks and responses. Geneva: 
WHO, 133-158.

Capstick, S., Whitmarsh, L., Poortinga, W., Pidgeon, N., \& Upham, P. (2014). International trends in public perceptions of climate change over the past quarter century. WIREs Clim Change, 6, 35-61. https://doi.org/10.1002/wcc.321

CDC. (2007). Malaria diagnosis and treatment in the Unites States.

Centers for Disease Control and Prevention (CDC, 2017). Frequently Asked Questions (FAQs), Global Health, Division of Parasitic Diseases and Malaria.

Citizen Report Card mechanism (SCORECARD), (2018). Assessment of public services in the sectors of water, health, education, and council services within the Kumbo Council Area, With the Technical and financial support of the National Community Driven Development Program (PNDP) in collaboration with the National Institute of Statistics (INS), Realized by Community Initiative for Sustainable Development (COMINSUD), May 2018, p.20.

Council Development Plan (CDP), (2011). Kumbo Council Development Plan, elaborated with the support of the National Community Driven Development Program (PNDP).

Craig, M. H., R. W. Snow, and D. le Seur (1999). A climate-based distribution model of malaria transmission in Sub-Saharan Africa. Parasitology Today, 15(3), 105-111. https://doi.org/10.1016/S0169-4758(99)01396-4

de Souza, D. K., Owusu, P. N., \& Wilson, M. D. (2012). Impact of Climate Change on the Geographic Scope of Diseases, Human and Social Dimensions of Climate Change, Prof. Netra Chhetri (Ed.) https://doi.org/10.5772/50646

Durrheim, D. N., Braack, L. E. O., Wane, S., \& Gammon, S. (1998). Risk of Malaria in Visitors to the Kruger National Park, South Africa. Journal of Travel Medicine, 5(4), 173-176. https://doi.org/10.1111/j.1708-8305.1998.tb00502.x

Fillinger, U., Ndenga, B., Githeko, A., \& Lindsay, S. W. (2009). Integrated malaria vector control with microbial larvicides and insecticide-treated nets in western Kenya: a controlled trial. Bulletin of the World Health Organization, 87(9), 655-65. https://doi.org/10.2471/ BLT.08.055632

Givemore, M., Brooke, B. D., Spillings, B., Essop, L., Hunt, R. H., Midzi, S., ... Malar, J. (2014). Field study site selection, species abundance and monthly distribution of anopheline mosquitoes in the northern Kruger National Park. South Africa, 13, 27.

Gubler, D. J., Reiter, P, Ebi, K. L., Yap, W., Nasci, R., \& Patz, J. A., (2001). Climate variability and change in the United States: potential impacts on vector and rodent-borne diseases. Environ Health Perpect (Ed.), 109(2), 223-233. https://doi.org/10.1289/ehp.109 $-1240669$

Gur, A. S., Kimengsi, J. N., Sunjo, T. E., \& Awambeng, A. E. (2015). The implications of climate variability on market gardening in Santa sub-division, North West region of Cameroon. Environment and Natural Resources Research, 5(2),14-23. https://doi.org/10.5539/enrr. v5n2p14

Huber, D. G., \& Gulledge, J. (2011). Extreme weather and climate change: Understanding the link, managing the risk. Arlington: Pew Center on Global Climate Change.

Innocent, N. M., Bitondo, D., \& Azibo, B. R. (2016). Climate Variability and Change in the 
Bamenda Highlands of North Western Cameroon: Perceptions, Impacts and Coping Mechanisms. British Journal of Applied Science \& Technology, 12(5), 1-18. https://doi.org/10.9734/BJAST/2016/21818

Kebede A, McCann J, Kiszewski A., \& Ye-Ebiyo Y (2005). New evidence of the effects of agro-ecologic change on malaria transmission. Am J Trop Med Hyg, 73, 676-680. https://doi.org/10.4269/ajtmh.2005.73.676

Kimengsi, J. N., \& Botanga, A. Q. (2017). Crop-Specific Response to Climatic Variability and Agricultural Planning Implications in North West Cameroon. Journal of Geography, Environment and Earth Science International, 13(2), 1-11. https://doi.org/10.9734/JGEESI/ $2017 / 38506$

Koenraadt, C. J. M., Githeko, A. K., \& Takken, W. (2004). The effects of rainfall and evapotranspiration on the temporal dynamics of Anopheles gambiae S.S. and Anopheles arabiensis in a Kenyan village. ActaTropica, 90(2), 141-153. https://doi.org/10.1016/j. actatropica.2003.11.007

Lieshout, M. V., Kovat, R. S., Livermore, M. I., \& Martens, J. P. (2004). Climate change and malaria analysis of the SRES climate and socio-economic scenarios. Global Environmental Change, 14(1), 87-99. https://doi.org/10.1016/j.gloenvcha.2003.10.009

Malakooti, M. A., Biomndo, K., \& Shanks, G. D. (1998). Reemergence of epidemic malaria in the highlands of western Kenya. Emerging infectious diseases, 4(4), 671. https://doi.org/10.3201/eid0404.980422

Mbouna, A. D., Tompkins, A. M., Lenouo, A., Asare, E. O., Yamba, E. I., \& Tchawoua, C. (2019). Modelled and observed mean and seasonal relationships between climate, population density and malaria indicators in Cameroon. Malaria Journal, 18(1), 359. https://doi.org/10.1186/s12936-019-2991-8

McNeil, D. G. (2008). Fake Malaria Drugs Emerging in Vulnerable Countries in Africa. The New York Times

McSweeney, C., New, M., \& Lizcano, G. (2008). UNDP Climate Change Country Profiles: Cameroon. United Nations Development Program and University of Oxford, Oxford.

MINSANTE. (2015). Ministry of Public Health: preemptive measures against malaria.

Mordecai, E. A., Ryan, S. J., Caldwell, J. M., Shah, M. M., \& LaBeaud, A. D. (2020). Climate change could shift disease burden from malaria to arboviruses in Africa. The Lancet Planetary Health, 4(9), e416-e423. https://doi.org/10.1016/S2542-5196(20)30178-9

Ndofor, E., Gool, T., \& Gillis, H. (2013). Laboratory diagnosis of malaria in the North West Region of Cameroon: analysis of limitations. Transactions of The Royal Society of Tropical Medicine and Hygiene, 107(6), 341-348. https://doi.org/10.1093/trstmh/trt025

Ngarakana-Gwasira, E. T., Bhunu, C. P., Masocha, M., \& Mashonjowa, E. (2016). Assessing the role of climate change in malaria transmission in Africa. Malaria research and treatment. https://doi.org/10.1155/2016/7104291

Ngum, W. J., Ongolo-Zogo, P., Tallah, E., Leke, R., \& Mbacham, W. (2010). Policy brief on scaling up malaria control interventions in Cameroon; Executive summary. Initiative of Cameroon Coalition Against Malaria (CCAM) and Centre for Development and Best 
Practices in Health (CDBPH), Obala Malaria Campaign Baseline Survey.

Nkuo-Akenji, T., Ntonifor, N. N., Ndukum, M. B., Kimbi, H. K., Abongwa, E. L., Nkwescheu, A., ... Titanji, V. P. K. (2006). Environmental factors affecting malaria parasite prevalence in rural Bolifamba, South- West Cameroon. African Journal of Health Sciences, 13(1), 40-46. https://doi.org/10.4314/ajhs.v13i1.30816

Olson, S. H., Gangnon, R., Elguero, E., Durieux, L., Guégan, J. F., Foley, J. A., \& Patz, J.A., (2009). Links between climate, malaria, and wetlands in the Amazon Basin. Emerging Infectious Diseases, 15(4), 659-662. https://doi.org/10.3201/eid1504.080822

Patz, J. A., Hulme, M., Rosenzweig, C., Mitchell, T. D., Goldberg, R. A., Githeko, A. K., ... \& Le Sueur, D. (2002). Regional warming and malaria resurgence. Nature, 420(6916), 627-628. https://doi.org/10.1038/420627a

Pemunta, N. V. (2013). The Social Epidemiology and Burden of Malaria in Bali Nyonga, Northwest, 4(1). https://doi.org/10.5195/HCS.2013.69

Perevedentsev, Y. P., Malkhazova, S. M., Aukhadeev, T. R., \& Shantalinsky, K. M. (2016). Medical and demographic consequences of climate change and the assessment of comfort level of weather-climatic conditions in the Volga federal district. Geography, Environment, Sustainability, 9(4), 63-76. https://doi.org/10.24057/2071-9388-2016-9-4-63-76

Peter, G. W., Battle, K. E., Bhatt, S., Smith, D. L., Eisele, T. P., Cibulskis, R. E., \& Hay, S. I. (2014). Declining malaria in Africa: improving the measurement of progress: Malaria Journal, 13, 39. https://doi.org/10.1186/1475-2875-13-39

Protopopoff N, Van Bortel W, Speybroeck N, Van Geertruyden J-P, \& Baza D, (2009). Ranking Malaria Risk Factors to Guide Malaria Control Efforts in African Highlands. PLoS ONE, 4(11), e8022. https://doi.org/10.1371/journal.pone.0008022

Roll Back Malaria (RBM). (2015). Safe human settlements and malaria; a prototype for sustainable development: fact sheets on malaria and the sdgs.

Roll Back Malaria (RBM)-Inclusive Societies Fact Sheet. (2015). Inclusive Societies and Malaria, Fact sheets on malaria and the SDGs, Lessons learned from responding to malaria globally: A prototype for sustainable development.

Sachs and Malaney (2002). The economic and social burden of malaria. Nature, 415, 680-685. https://doi.org/10.1038/415680a

Sunjo, E. T., Kometa, S. S., \& Amawa, S. G. (2012). The implications of rainfall variability on cattle and milk production in Jakiri sub division, North West region, Cameroon. Journal of Agricultural Science, 4(10), 237-243. https://doi.org/10.5539/jas.v4n10p237

Sutherst, R. W. (2004). Global Change and Human Vulnerability to Vector-Borne Diseases. CLINICAL MICROBIOLOGY REVIEWS, 17(1), 136-173. https://doi.org/10.1128/CMR.17.1. 136-173.2004

Tchuinkam T, Simard F, Lélé-Defo E, Téné-Fossog B, Tateng-Ngouateu A, and Antonio-Nkondjio C (2010). Bionomics of Anopheline species and malaria transmission dynamics along an altitudinal transect in Western Cameroon. BMC Infect Dis, 10, 119-30.

The World Bank Group (2019). Population, total- Cameroon.

Ting T. H., \& Ming L. T. (2005). Effects of climate change on disease epidemics and social 


\section{Macrothink}

instability around the world. Department of Epidemiology, University of North Carolina.

Tonui, W. K. (2008). Environmental determinants of patterns and trends of occurrence of unstable malaria in Kericho District Kenya, Ph.D. Thesis, Kenyatta University, Kenya.103-108.

Tume, S. J. P. (2019). Standardized precipitation valuation of water resources vulnerability to climate variability on the Bui Plateau, NorthWest Cameroon. Environment and Ecology Research, 7(2), 83-92. https://doi.org/10.13189/eer.2019.070202

Tume, S. J. P., Nyuykigham, M. D., Kongnso, M. E., Dzeaye, B. A., Nsaikii, M. F., \& Njodzeka, N.G. (2019). Food crop vulnerability to climate variability and change at the household level in Bui Division, Northwest Cameroon. Chapter in the Book "Climate Change and Sub-Saharan Africa: The vulnerability and adaptation of food supply chain actors". Edited by John K.M. Kuwornu, School of Environment, Resources and Development, Asian Institute of Technology, Thailand.

Wandiga, S. O., Opondo, M., Olago, D., Githeko, A., Gthui, F., Marshall, M., ... ApindiAchola, P. (2006). Vulnerability to climate induced highland malaria in East Africa, AIACC Working Papers, USA.

World Health Organization (WHO). (2014). World malaria report 2014, who global malaria programme, WHO Library Cataloguing-in-Publication Data.

World Health Organization (WHO). (2015). World malaria report 2015, WHO global malaria programme, WHO Library Cataloguing-in-Publication Data.

World Health Organization (WHO). (2020). Malaria Key facts.

Wua, X., Lu, Y., Zhouc, S., Chen, L., and Xu, B. (2016). Impact of climate change on human infectious diseases: Empirical evidence and human adaptation. Environment International, 86, 14-23. https://doi.org/10.1016/j.envint.2015.09.007

Wuyi, W., Linsheng, Y., Yonghua, L., Hairong, L., \& Bixiong, Y. (2010). The Environmental Challenge And Health Security In China. Geography, Environment, Sustainability, 3(3), 42-55. https://doi.org/10.15356/2071-9388_03v03_2010_04

\section{Copyright Disclaimer}

Copyright for this article is retained by the author(s), with first publication rights granted to the journal.

This is an open-access article distributed under the terms and conditions of the Creative Commons Attribution license (http://creativecommons.org/licenses/by/4.0/). 